\title{
Study on the Influence of Price Fluctuation of Main Equipment and Materials on Cost of Power Grid Project
}

\author{
Peng Rong ${ }^{1 *}$, Guoming Liu ${ }^{1}$, Qing Wang ${ }^{1}$, Yong Dai ${ }^{1}$, Wei Zhang ${ }^{1}$, Han Zhang $^{1}$, Yi Wang ${ }^{1}$ \\ ${ }^{1}$ State Grid Shandong Electric Power Company Taian Power Supply Company, Shandong Province, Taian; 271000, China
}

\begin{abstract}
The price of equipment and materials is affected by various internal and external factors, and the price fluctuates greatly. The historical price information cannot reflect the real price of equipment and materials. There is a big difference between the feasibility estimate based on the analysis of historical price information and the actual project cost, which leads to a high project balance and reduces the investment benefit of the company. Taking the substation project as an example, this paper analyzes the change law of the main equipment price in recent years, studies the impact of the price change of the main equipment on the cost, assists the project cost prediction, supports the analysis and evaluation of the feasibility study estimation, reduces the balance rate, optimizes the investment strategy, reduces the project investment risk, and improves the lean management level of the project investment.
\end{abstract}

\section{Research background and existing problems}

In the early stage of project construction, it is often necessary to analyze the rationality of the feasibility study estimate. In order to support the analysis of the feasibility study estimate, the relevant departments of power grid enterprises need to issue the information price of equipment and materials regularly according to the historical price information of engineering equipment and materials. However, the price of equipment and materials is affected by many internal and external factors, and the price is uncertain. Historical price information can not better reflect the actual price of equipment and materials. Therefore, it is necessary to analyze the price of power grid engineering equipment and materials by analyzing the price of equipment and materials. It is not only one of the important ways to improve the accuracy of project cost prediction, but also help to improve the efficiency and efficiency of investment and improve the lean management level of the company.

\section{Analysis on price change law of main equipment in substation project}

In the construction of power grid engineering, there are many kinds of equipment and materials involved, and it is difficult to collect data. Collect 67 pieces of data related to the cost of the new substation project in the $220 \mathrm{kV}$ and $500 \mathrm{kV}$ completed accounts of the Shandong company from 2016 to 2019, analyze the correlation between the unit cost and the cost of the main equipment and materials of the substation project, and select which has a greater impact on the cost of the substation project and the main equipment transformers and circuit breakers with easy data are used as the research object to analyze the historical change law. According to the collected data, the annual average static investment, average unit price of main transformer, average unit price of high-voltage side circuit breaker, average unit price of medium voltage side circuit breaker and low-voltage side circuit breaker are calculated according to the collected data. The change trend of unit price of each equipment is shown in the following figure: 


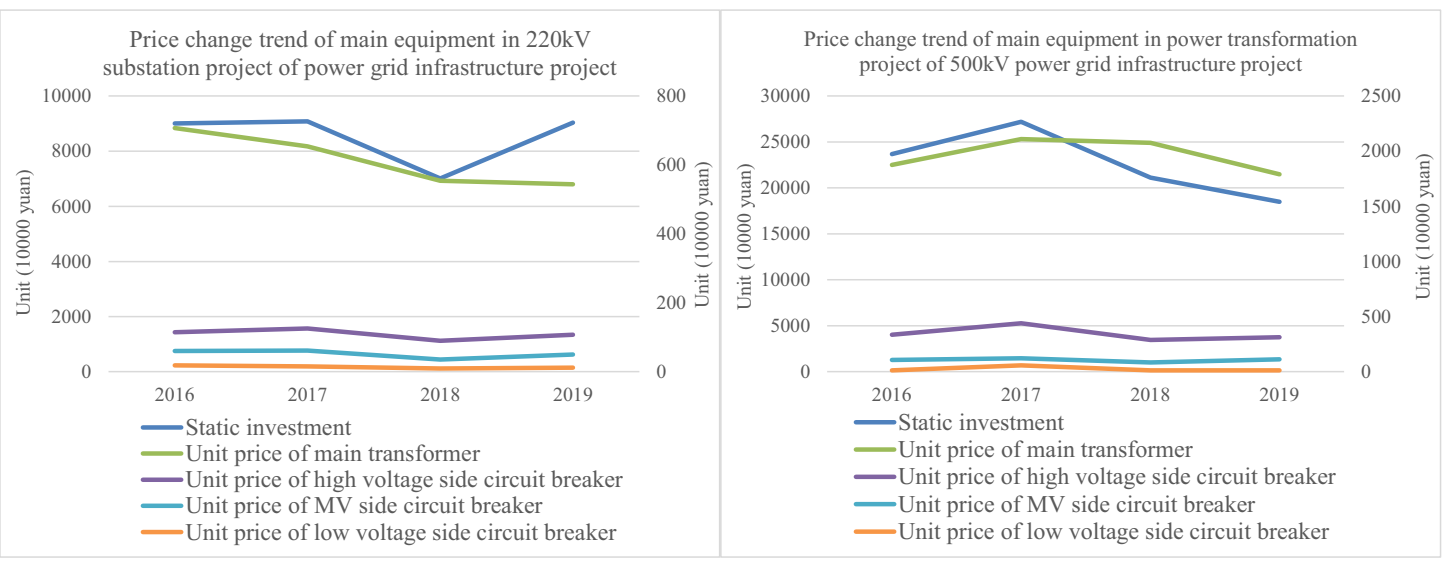

Fig 1. Price trend of major equipment

As can be seen from the figure, from 2016 to 2019, the static investment of substation project of $220 \mathrm{kV}$ and $500 \mathrm{kV}$ power grid infrastructure projects and the prices of main equipment decreased in 2018, and 2017 was the year with the highest price. The change trend of main transformer unit price, high voltage side circuit breaker unit price, medium voltage side circuit breaker unit price, low voltage side circuit breaker unit price change trend is basically consistent with the static investment change trend. Therefore, it can be inferred that the price change of main equipment will have a certain impact on the static investment. It is necessary to further study the impact of the price change of main equipment on the static investment.

\section{Analysis on price change law of main equipment in substation project}

At present, there are qualitative analysis methods and quantitative analysis methods on the impact of main equipment price changes on the total cost. Among them, the quantitative analysis methods mainly include price index method, artificial intelligence algorithm and other methods. In this paper, the regression analysis method is used to quantitatively study the influence of main equipment price changes on the cost.

Collect 290 pieces of main equipment price and actual cost information data of $35-500 \mathrm{kV}$ new substation project of Shandong company from 2016 to 2019, and study the impact of price changes of main equipment and materials on the total project cost.

\subsection{Analysis of the correlation between the price of main equipment and the cost of substation project}

SPSS software was used to analyze the correlation between static investment of substation project and unit price of major equipment. The results are as follows:

\begin{tabular}{|c|c|c|c|c|c|c|c|}
\hline \multicolumn{8}{|c|}{ Relevance } \\
\hline & & $\begin{array}{c}\text { Static } \\
\text { investment }\end{array}$ & \begin{tabular}{|c|} 
Price of \\
single high \\
voltage \\
reactor(10000 \\
yuan/group) \\
\end{tabular} & $\begin{array}{c}\text { Unit price } \\
\text { of low } \\
\text { voltage } \\
\text { side(10000 } \\
\text { yuan/set) } \\
\end{array}$ & $\begin{array}{c}\text { Unit price of } \\
\text { MV side } \\
\text { circuit } \\
\text { breaker(1000 } \\
0 \text { yuan / set) } \\
\end{array}$ & $\begin{array}{l}\text { Unit price of } \\
\text { high voltage } \\
\text { side circuit } \\
\text { breaker(1000 } \\
0 \text { yuan / set) } \\
\end{array}$ & $\begin{array}{l}\text { Unit price of main } \\
\text { transformer(Thre } \\
\text { e phase, } 10000 \\
\text { yuan / set) }\end{array}$ \\
\hline \multirow{3}{*}{ Static investment } & Pearson correlation & 1 & -0.046 & $.491^{* \prime}$ & $.834^{\prime \prime}$ & $.859^{* *}$ & $.891^{* \prime}$ \\
\hline & Sig. (Double tail) & & 0.458 & 0 & 0 & 0 & 0 \\
\hline & Number of cases & 290 & 258 & 290 & 256 & 290 & 290 \\
\hline \multirow{3}{*}{$\begin{array}{l}\text { Price of single high } \\
\text { voltage react or }(10000 \\
\text { yuan / group) }\end{array}$} & Pearson correlation & -0.046 & 1 & -0.028 & 0.009 & -0.041 & -0.046 \\
\hline & Sig. (Double tail) & 0.458 & & 0.657 & 0.885 & 0.51 & 0.465 \\
\hline & Number of cases & 258 & 258 & 258 & 248 & 258 & 258 \\
\hline \multirow{3}{*}{$\begin{array}{l}\text { Unit price of low } \\
\text { voltage side( } 10000 \\
\text { yuan / set) }\end{array}$} & Pearson correlation & $.491^{*}$ & -0.028 & 1 & $.461^{* *}$ & $.470^{*+}$ & $.426^{*}$ \\
\hline & Sig. (Double tail) & 0 & 0.657 & & 0 & 0 & 0 \\
\hline & Number of cases & 290 & 258 & 290 & 256 & 290 & 290 \\
\hline \multirow{3}{*}{$\begin{array}{l}\text { Unit price of MV side } \\
\text { circuit breaker( } 10000 \\
\text { yuan / set) }\end{array}$} & Pearson correlation & $.834^{*+}$ & 0.009 & $.461^{* *}$ & 1 & $.881^{* *}$ & $.798^{*+}$ \\
\hline & Sig. (Double tail) & 0 & 0.885 & 0 & & 0 & 0 \\
\hline & Number of cases & 256 & 248 & 256 & 256 & 256 & 256 \\
\hline \multirow{3}{*}{$\begin{array}{l}\text { Unit price of high } \\
\text { voltage side circuit } \\
\text { breaker(10000 yuan / } \\
\text { set) }\end{array}$} & Pearson correlation & $.859^{* \prime}$ & -0.041 & $.470^{* *}$ & $.881^{* *}$ & 1 & $.809^{*}$ \\
\hline & Sig. (Double tail) & 0 & 0.51 & 0 & 0 & & 0 \\
\hline & Number of cases & 290 & 258 & 290 & 256 & 290 & 290 \\
\hline \multirow{3}{*}{$\begin{array}{l}\text { Unit price of main } \\
\text { transformer(Three } \\
\text { phase, } 10000 \text { yuan / } \\
\text { set) }\end{array}$} & Pearson correlation & $.891^{* \prime}$ & -0.046 & $.426^{* \prime}$ & $.798^{* *}$ & $.809^{* \prime}$ & 1 \\
\hline & Sig. (Double tail) & 0 & 0.465 & 0 & 0 & 0 & \\
\hline & Number of cases & 290 & 258 & 290 & 256 & 290 & 290 \\
\hline
\end{tabular}

**. At the 0.01 level (two-tailed), the correlation is significant.

Fig 2. Analysis results of correlation between static investment of substation project and unit price of main equipment 
According to the above correlation analysis results, it can be seen that the static investment has strong correlation with the unit price of main transformer, highvoltage circuit breaker, medium voltage circuit breaker and low-voltage circuit breaker, but not with the price of high-voltage reactor. From the results of correlation analysis, it can be seen that there is a certain correlation between independent variables, so it is necessary to test whether there is multicollinearity among independent variables.

\subsection{Analyze whether there is multicollinearity between independent variables}

SPSS software was used to analyze the existence of multicollinearity among independent variables, and the analysis results were as follows:

\section{Coefficient $^{\mathrm{a}}$}

\begin{tabular}{|c|c|c|c|}
\hline \multirow{2}{*}{ Model } & & \multicolumn{2}{|c|}{ Collinear statistics } \\
\hline & & Tolerance & VIF \\
\hline & (Constant) & & \\
\hline & $\begin{array}{l}\text { Unit price of main } \\
\text { trans former(Three phase, } 10000 \\
\text { yuan/set) }\end{array}$ & 0.317 & 3.151 \\
\hline & $\begin{array}{l}1 \text { Unit price of high voltage side } \\
\text { circuit breaker( } 10000 \text { yuan/ set) }\end{array}$ & 0.195 & 5.135 \\
\hline & $\begin{array}{l}\text { Unit price of MV side circuit } \\
\text { breaker(10000 yuan/ set) }\end{array}$ & 0.198 & 5.05 \\
\hline & $\begin{array}{l}\text { Unit price of low voltage } \\
\text { side( } 10000 \text { yuan / set })\end{array}$ & 0.775 & 1.29 \\
\hline
\end{tabular}

Fig 3. Results of multicollinearity analysis among independent variables

In general, if the tolerance (Tol) is less than 0.1 or variance inflation factor (VIF) is greater than 10 , then collinearity exists. According to the analysis results in the table above, the tolerance of all independent variables is greater than 0.1 , and the VIF index is less than 10 . It can be preliminarily considered that the collinearity problem

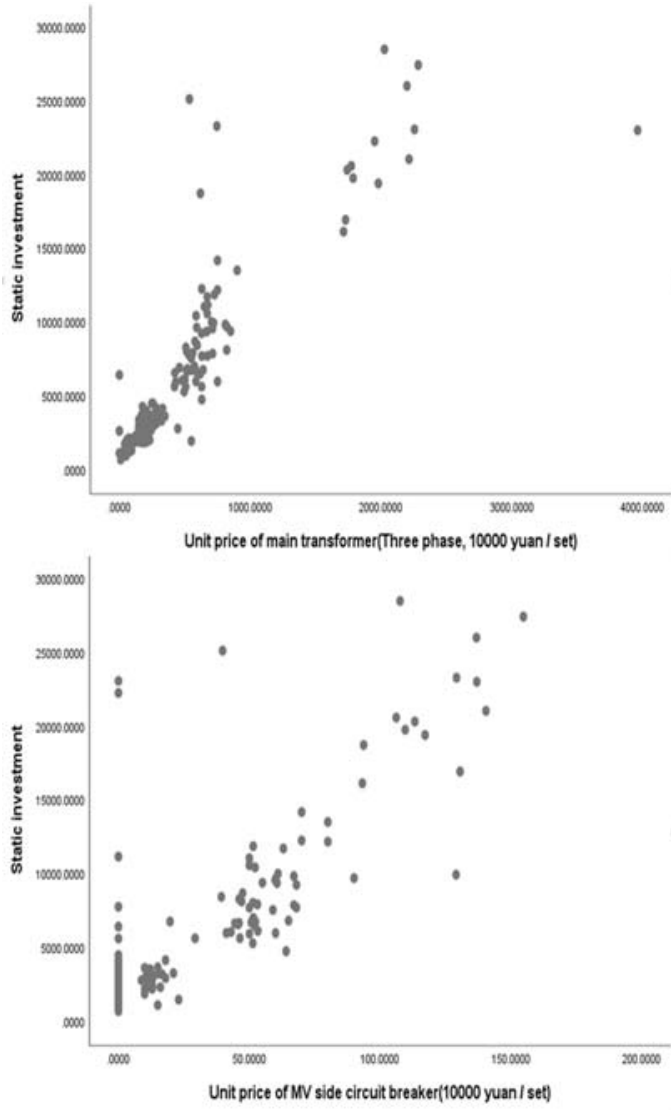

can be ignored.

\subsection{Clarify the relationship between the cost and the price of the main equipment in the substation project}

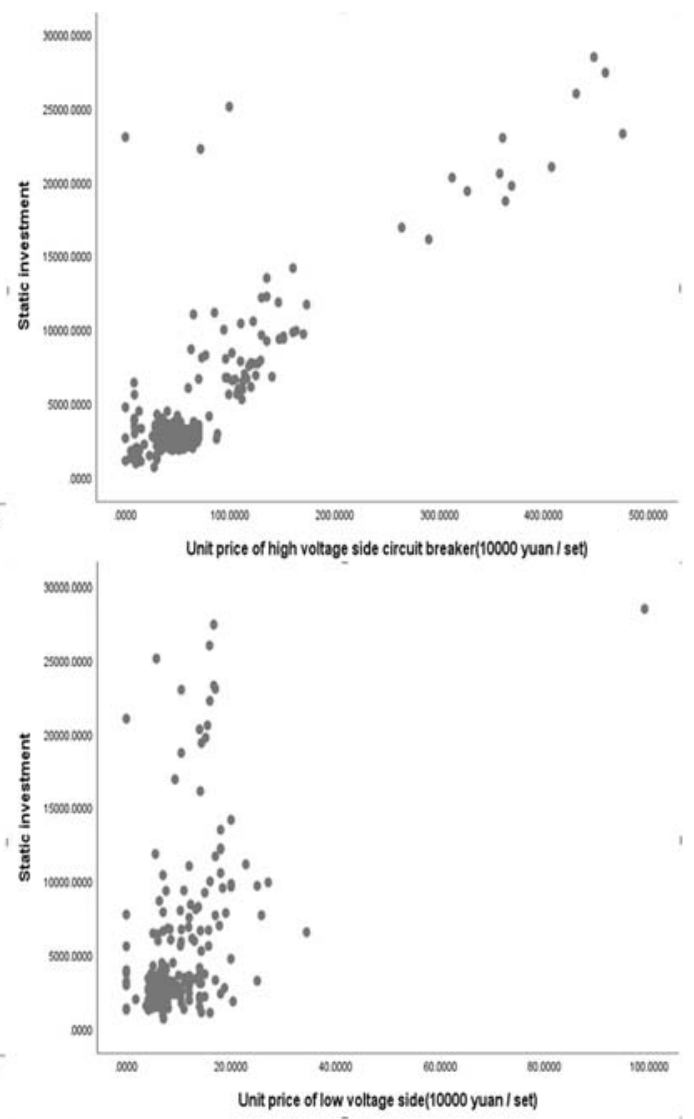

Fig 4. Scatter diagram of static investment and main equipment price of substation project 
Several factors with strong correlation between substation project and cost are extracted, and the relationship between main material unit price and cost is checked through scatter diagram. It can be seen from the above figure that there is obvious linear relationship between unit price of main transformer, unit price of circuit breaker at high voltage side, unit price of circuit breaker at medium voltage side, unit price of circuit breaker at low voltage side and static investment.

\subsection{Construction of regression model between main equipment price and static investment of substation project}

Based on the above analysis, a linear regression model is constructed between the price of major equipment in power transformation engineering and the static investment. The results are as follows:

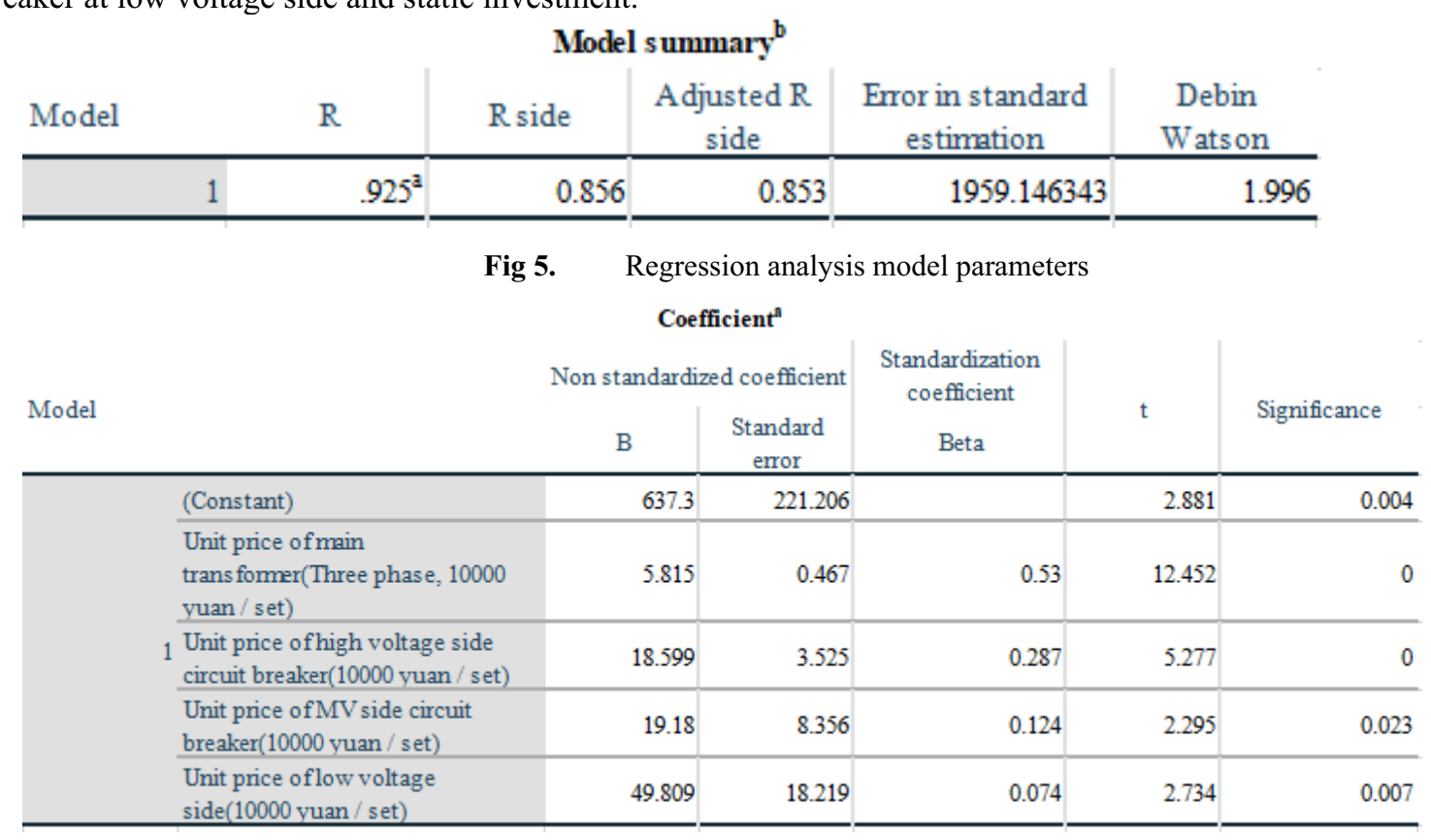

Fig 6. Regression analysis model coefficients

According to the above results, the linear regression model between static investment (a) and unit price of main transformer (b), unit price of high voltage circuit breaker (c), unit price of medium voltage circuit breaker (d) and unit price of low voltage circuit breaker (e) is established: $a=637.3+5.815 b+18.599 c+19.18 d+49.809 e$.
Select one completed final account project of the same type in 2018 and 2019 respectively (220-A3-3 is adopted for the general design scheme) with the same number of equipment, and the basic information of the main equipment price and static investment is as follows:

\subsection{Application}

Table1. Basic information of major equipment prices and static investment of the project

\begin{tabular}{|c|c|c|c|c|c|c|c|}
\hline $\begin{array}{l}\text { Year of } \\
\text { complet } \\
\text { ion }\end{array}$ & $\begin{array}{c}\text { Voltage } \\
\text { level } \\
(\mathrm{kV})\end{array}$ & $\begin{array}{l}\text { The general } \\
\text { design scheme } \\
\text { is adopted }\end{array}$ & $\begin{array}{l}\text { Unit price of } \\
\text { main } \\
\text { transformer } \\
\text { (three phase, } \\
10000 \text { yuan / } \\
\text { set) }\end{array}$ & $\begin{array}{l}\text { Unit price of } \\
\text { high voltage } \\
\text { side circuit } \\
\text { breaker ( } 10000 \\
\text { yuan / set) }\end{array}$ & $\begin{array}{l}\text { Unit price of } \\
\text { MV side circuit } \\
\text { breaker (10000 } \\
\text { yuan / set) }\end{array}$ & $\begin{array}{l}\text { Unit price of } \\
\text { low voltage } \\
\text { side (10000 } \\
\text { yuan / set) }\end{array}$ & $\begin{array}{c}\text { Static } \\
\text { investme } \\
\text { nt }\end{array}$ \\
\hline 2018 & 220 & $220-\mathrm{A} 3-3$ & 630 & 123 & 50 & 17 & 7677 \\
\hline 2019 & 220 & 220-A3-3 & 424 & 102 & 45.64 & 12.56 & 6538 \\
\hline \multicolumn{3}{|c|}{ Price changes of major equipment } & -206 & -21 & -4.36 & -4.44 & -1139 \\
\hline
\end{tabular}

According to the regression analysis model, the impact of price changes of main equipment in 2019 compared with that in 2018: $637.3+5.815 *(-206)+18.599 *(-21)+$ $19.18(-4.36)+49.809 *(-4.44)=-12.55946$ million yuan. The impact amount is close to the actual static investment deviation of - 11.39 million yuan in 2019 and
2018, with a difference of only 1.17 million yuan, with a deviation of $10 \%$, which is within a reasonable range. 


\section{Conclusion}

Taking the power transformation project of power grid infrastructure project as an example, this paper analyzes the change law of the price of main equipment in the power transformation project from 2016 to 2019, explores how to quantify the impact of the price fluctuation of the main equipment of the substation project on the total cost of the substation project, and constructs a linear regression model, which can be used for feasibility study, analysis and evaluation, and project cost prediction, so as to optimize the investment strategy and reduce the project investment wind Insurance, improve the lean management level of project cost.

\section{References}

1. Wu, M, Q. (2018) Study on Influencing Factors and Prediction Model of Equipment and Material Price in Power Grid Engineering. North China Electric Power University.

2. Lu, Y. (2016) Research on Dynamic Management Model of Power Grid Project Cost Based on Target Control. North China Electric Power University.

3. Yu, C. (2016) Study on the Influencing Factors and Evaluation Model of Power Grid Project Cost. North China Electric Power University.

4. Liu, X. (2017) Research on Cost Control Evaluation of Power Grid Project of Tianjin Electric Power Company. Tianjin University.

5. Wu, D. (2019) Research on Application of Theory and Method Model of Transmission and Distribution Project Cost Analysis. Experience Exchange.

6. Zhao, G, Z. (2019) Influence of Material Price Change on Project Cost and Control Strategy. Hot Spot Perspective.

7. He, L. (2017) Study on the Influence of Building Material Price Fluctuation on Construction Cost. Zhengzhou University. 